\title{
Conceptualizing and Measuring Prospect Wants: Understanding the Source of Brand Preference
}

\author{
Geraldine Fennell • Greg M. Allenby
}

Published online: 12 December 2013

(C) Springer Science+Business Media New York 2013

\begin{abstract}
Prospect wants originate upstream from the marketplace, in the context of everyday life and work. Researchers in marketing attempt to read wants by measuring and decomposing consumer preferences for marketplace offerings. In this paper, we show that consumer preference for offerings reflects an interaction between motivating conditions that prompt users to action, and capability of a brand's attributes to address the source of the motivation. A hierarchical Bayes conjoint model is proposed for measuring motivating wants that exist upstream from the marketplace and instrumental wants that are expressed as reactions to marketplace offerings. The model is illustrated with data from a national survey of the concerns and interests that prompt prospects to brush their teeth and their preference for toothpaste attributes .
\end{abstract}

Keywords Conjoint analysis - Motivation - Part-worth . Hierarchical Bayes

\section{Introduction}

The concept of wants is central to the discipline of marketing and its role in guiding management to make goods

Electronic supplementary material The online version of this article (doi:10.1007/s40547-013-0001-9) contains supplementary material, which is available to authorized users.

G. Fennell · G. M. Allenby $(\bowtie)$

Fisher College of Business, Ohio State University,

Columbus, USA

e-mail: allenby.1@osu.edu

G. Fennell

e-mail: fenl@ymail.com and services that people will want to buy. Wants are typically associated with actual or hypothetical marketplace offerings (e.g., wanting a brand of toothpaste, soda, a pet) and associated attributes (e.g., good breath freshening, citrus flavored, easy care). The importance of marketplace, or instrumental, wants is measured with data that reflect consumer preferences for real and hypothetical offerings, often using statistical models (e.g., conjoint analysis) that decompose the preference for an offering into utility part-worths associated with features and attributes.

Researchers in marketing have a long history of studying wants and drivers of brand preference. Analysis has historically focused on instruments used in achieving a desired goal and, more recently, the goal itself. While there is wide acceptance for a view of motivation as arising from disparity between an individual's current state and their imagined, desired state [1,2], theory and research have favored studying the latter state to the virtual neglect of the former state. For example, the analysis of benefits [19], goals $[7,16,17,20]$, and means-end chains [26] describes the objects, attributes, or the activities that are instrumental for achieving desired imagined states or the imagined states themselves. Such analysis does not investigate the motivating conditions that allocate and direct an individual's resources in the first place, which describe the current state of the individual. The individual is simply assumed to be motivated toward the imagined state. While the distinction between motivation and goals is recognized, the implication of the distinction for understanding prospective user wants has not been developed.

In this paper, we report an approach to measuring motivating wants that describes the current state of the individual and compare it to a traditional analysis of instrumental wants associated with the imagined state of the individual. Our analysis separately examines both where one is coming 
from and where one is headed, providing insight into conditions for which a brand is preferred. When no variable that describes the current (motivating) state is included, analysis of consumer preferences leaves much ambiguity regarding the nature of the motivating conditions, which are the conditions that valued goods and services must address. There exists much literature in psychology and marketing on what is being pursued, but not how the current state contributes or gives rise to the pursuit.

For example, consumers may report that they want to "look good" and "feel good" in relation to the goal of losing body weight. Such items are end points and do not state the conditions that lead to wanting to "look good." Is the person overweight over all their body or just in particular places? Which places? Does their shortness/height enter their sense of not looking good? Do nonapparent muscles enter their concern? Do they have concerns about hanging skin, if they lose weight? Is their sense of not feeling good due to their having failed to take care of their appearance? Do they feel bad because they cannot move easily due to being overweight? Has their present condition happened slowly or rapidly? Knowing where one is coming from provides guidance to manufacturers for brand (re)formulation and the creation of media content that is often not available from knowing only the imagined state.

As a secondary issue, we provide evidence that the measurement of attribute and benefit importance is confounded with brand beliefs. More specifically, we find that the partworth of an attribute-level is low when the attribute-level is judged to not describe the current array of brands. This is not true, however, for the presence of the motivating conditions, which is shown to be unrelated to brand beliefs. Studying motivating conditions therefore provides a platform for assessing the extent to which the current range of brand offerings and their attributes are responsive to the motivating conditions present.

Finally, we demonstrate that motivating conditions can be combined with information on desired attributes and benefits to yield improved predictions of brand preference. Our analysis extends the work of Yang et al. [30] who demonstrate the existence of diverse motivating conditions across individuals within, as well as intraindividual variation in motivations across, objectively specified environments.

The remainder of this paper is organized as follows: In the next section, we lay out the conceptual differences between motivating wants that describe the current state of the individual and instrumental wants associated with the attributes and benefits of marketplace offerings and the imagined state. By marketplace or instrumental wants, we refer to wants inferred from reactions to goods and services offered at the retailer, the box office, or on the Internet. In Section 3, we describe a method of measuring motivating wants, illustrating the method with an analysis of the conditions present in the context for brushing one's teeth. Data and parameter estimates from our measurement model are described in Section 4, and in Section 5, we present findings from our motivational analysis, along with those from a traditional conjoint analysis of toothpaste. In Section 6, we offer a conceptual discussion of the information contained in motivating wants and marketplace preferences.

\section{Conceptualizing and Measuring Prospect Wants}

Figure 1 displays an abbreviated model of action that focuses attention on key aspects of our analysis. Personal and environmental systems intersect to produce motivating conditions that lead to desired benefits and attributes and eventually to marketplace action including brand choice. Motivating conditions allocate an individual's resources to a domain of action and prompt them to adjust their relationship with the environment within that domain. For example, an individual may feel cold because of a drop in the ambient temperature and become motivated to ease their discomfort. The individual may look to remedies at hand (e.g., close the window) and/or marketplace offerings (e.g., a sweater) to improve their condition or, weighing resources required against discomfort, may decide that adjustment is not cost-worthy, and action is not forthcoming. Finally, ex post and ex ante analysis is relative to the product offering.

Our model of motivation and behavior is consistent with Lewin's [23] formulation of behavior that comprises person $(\mathrm{P})$, environment $(\mathrm{E})$, situation $(\mathrm{S})$, and behavior $(\mathrm{B})$. Person and environment jointly contribute to a situation as perceived (i.e., $S=f(P, E)$ ), and behavior is assumed to arise from within the situation (i.e., $B=f(S)$ ). Other authors (e.g., $[8,11])$ have used person-situation models of the form of $\mathrm{B}=\mathrm{f}(\mathrm{P}, \mathrm{S})$, which describes variation in behavior but fails to provide access to how the person perceives the environment; such a formulation results in ambiguity regarding the current state of the individual.

For example, Dickson [11] identifies benefits and features of suntan lotion that arise from various person (e.g., young children, teenagers, women, men)-situation (e.g., beach/boating sunbathing, home-poolside sunbathing, sunlamp sunbathing, snow skiing) settings. Situation benefits and features include items like "windburn protection," "large pump dispenser," "won't stain wood/concrete," and "antifreeze formula" that describe the imagined state and instrumental attributes, but do not describe the current state of the individual. Examples of motivating conditions that describe the current state of the individual include items such as "I'm concerned that my pale skin makes me look unhealthy," "If I don't look tanned, I'll feel out of it in company with friends who've been on vacation," and "The 
Fig. 1 Model of action and brand use

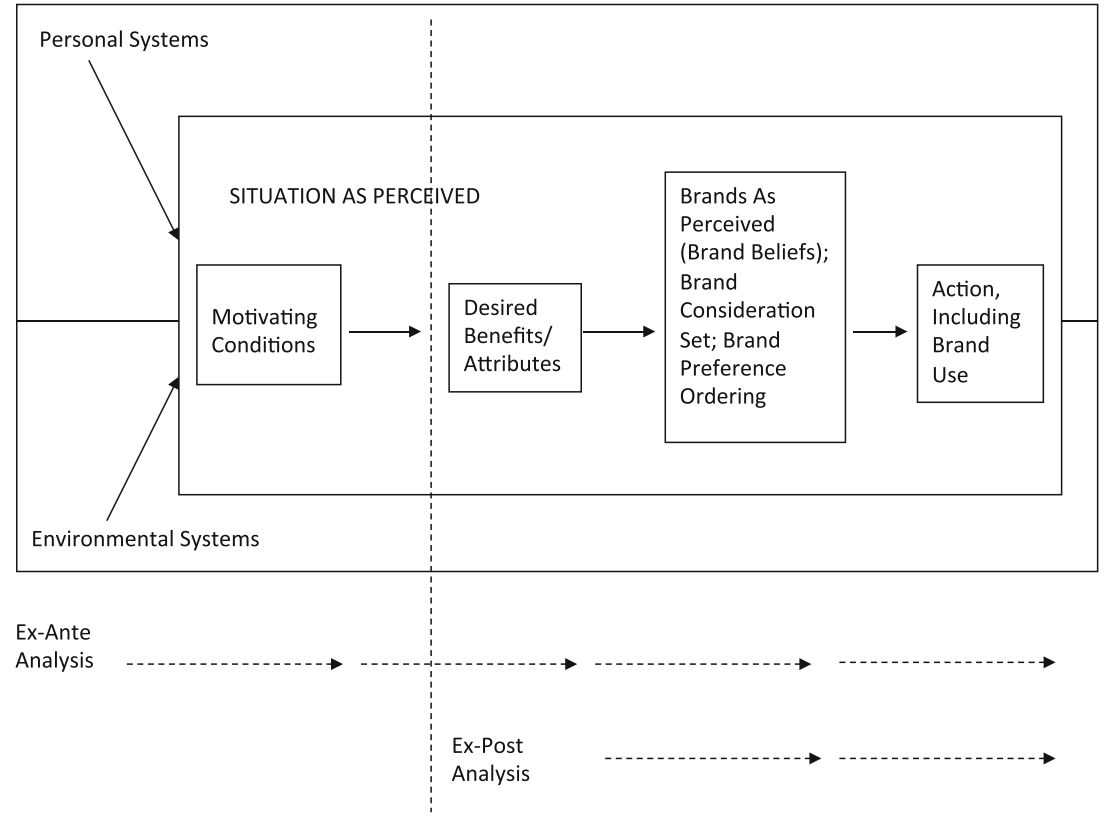

season changes, and it's time to look tanned." Such items describe the motivating features of the individual's current state (i.e., where the individual is coming from), which specify features of the desired state (i.e., where the individual is going to).

Person and environment are viewed as comprising multiple systems, allowing for a small subset of each intersecting to produce motivating conditions by instating a desired state, i.e., comparing the present with an imagined state, the individual is ready to allocate resources to bring about the imagined state, expecting or hoping to improve their state of being. Viewed from left to right, the model displayed in Fig. 1 represents a behavioral process that allocates an individual's resources to a substantive domain (e.g., feeling lonely) and desired state (e.g., reconnecting with friends) and directs how the individual deploys those resources within that domain, favoring actions and objects (e.g., attending a picnic, making a phone call, writing a letter) likely to bring about an improved state of being. In Fig. 1, motivating wants correspond to motivating conditions, and the instrumental wants they specify correspond to desired benefits and attributes. The terms ex ante and ex post superimposed in Fig. 1 refer respectively to two concepts of demand. Ex-post represents a view of demand where the offering is given; ex-ante is a view of demand based on conditions that pre-exist the offering [13].

Our model of behavior is intended to describe a single occasion of an activity. Motivation is operationalized as the concerns and interests relevant to an activity, in contrast to the term "motive," which psychologists have used to refer to a trait-like variable intended to apply across activity and over time (e.g., achievement motive [25]). Moreover, it differs from approaches to studying goals (e.g., [6, 20, 29]) where interest focuses on identifying a range of goals, from high levels of abstraction to specific features. Our model is intended to help investigate concrete concerns and interests that allocate human resources, not higher-order constructs that are sometimes of focus of interest.

Consider, for example, the use of means-end theory [26] to understand drivers of brand preference. The theory assumes that people choose product offerings that can be instrumental to achieving desired consequences. Using a procedure of iteratively asking the respondent to state why each answer is important, they obtain high-order interpretations of what people want. Regarding alcoholic beverages, for example, Reynolds and Gutman report that respondents reply with reasons such as "to socialize," "avoid getting drunk," and "thirst quenching," often arriving ultimately at a value statement expressed at a high level of abstraction. The focus is not on describing the present state in concrete terms. For the respondent interested in not getting drunk, does he have a medical condition where alcohol is problematic? Is he a problem drinker or a designated driver on that occasion? A producer bent on responding to the conditions that prospect face requires greater guidance than that offered by simply knowing that the goal is to "avoid getting drunk." In this paper, we describe a method for studying the concrete wants of an individual's present state and compare it to the current approach of describing wants in terms of preference for product attributes and benefits. 


\subsection{Generating Candidate Items}

We employ Fennell's [14] motivational formulation to generate items for study. This formulation comprises seven qualitatively distinct classes as described in Table 1, i.e., five simple classes and two complex classes that involve multiple conditions. The class structure is used as a guide for generating candidate items expressed as concerns and interests and is not used to impose any structural relationship among the items in our analysis. It describes qualitatively distinct kinds of motivating condition that may be present in the context for an individual's action. Compared to the usual purely empirical approach, often guided only by the existing brand array, the availability of such a set of classes facilitates the researcher/analyst checking if current offerings are responsive to the range of qualitatively distinct motivating conditions. Also included in Table 1 are examples of concerns and interests for selected activities. Such examples illustrate that the motivating classes provide the structure of different kinds of condition that may allocate resources in any domain of action.

The classes originate in the settings that researchers use to instigate behavior for the experimental study of learning in lower animals and are adapted for use in studying human behavior. The first three classes in Table 1 are about moving away from an undesirable state of affairs that is present for the individual, whether currently experienced (class 1), imagined to occur at some future time (class 2), or brought to focal attention only by default (class 3 ). For example, an individual may engage in oral hygiene activities because of concern about bad breath, dull teeth, or to deal with the current conditions that lead to cavities (class 1); because of concerns about what their peers, or the actor, themselves, may think if they did not brush (class 2); or simply as relatively mindless routine (class 3 ).

Where in the case of the first three classes, the individual moves away from the source of the motivation, in the case of the next two classes, the individual moves toward the source of the motivation. Class 4 describes interests that involve mental exploration as, for example, in a hobbiest orientation to the focal activity. Class 5 deals with the pursuit of sensory enjoyment. An example of a class 4 motivation for toothbrushing would be interest in knowing about the science of oral hygiene, and an example of a class 5 motivation would be enjoying sensory experiences from brushing.

The final two classes in Table 1 describe complex conditions in which the individual is motivated to act but is deterred from doing so either because of expected harmexcessive cost in the broadest sense (class 6)-or expected dissatisfaction (class 7). These two classes combine motivations to act that occur outside the marketplace, and the expected outcome of using some version of the product. An example of a class 6 item written for toothbrushing would be agreement with the statement that toothpastes taste too strong or cost too much. An example of a class 7 item written for toothbrushing would be toothpastes are not strong enough to prevent cavities.

Candidate items are generated from focus group transcripts and the analysis of brand claims in broadcast commercials and product packages. Prior to conducting qualitative research, the analyst is well advised to consider how the various kinds of motivation may be manifested in the context for the focal activity. Only prospects, i.e., respondents who qualify as predisposed to buying/using the focal product category, are included in qualitative and quantitative phases.

- In the case of class 1 , for example, with regard to the focal activity, the analyst will generate examples of grave, unpleasant circumstances, or unusual special cases, whose occurrence is outside the actor's control in the short run. Among others, "grave" may refer to intensity, speed of onset, or frequency of some condition an individual dislikes. It is useful to remember that, where common usage invokes the verb, "prevent," e.g., prevent tooth decay, prevent engine wear-out, the motivating element that must be dealt with is, in fact, something that is occurring at the present time, for example, substances present in the mouth that are harmful to the teeth and gums or wear and tear due to moving metal parts. Although many examples reflect conditions in the relevant environment as perceived, personal elements, such as values that the individual believes are being thwarted, may also contribute examples.

- As regards class 2, at issue are examples of individuals experiencing discomfort while anticipating how they will judge themselves, or how they imagine others will judge them, in the event that they fail to act appropriately. Examples comprise imagined censure or failure to gain praise from self or others. Reflecting on examples of psychology's major constructs, e.g., traits, roles, and self-concepts, as they may be experienced in regard to the focal activity, is a useful source of ideas.

- As regards class 3, at issue is the believed presence of a state of affairs that requires only minimal maintenance for normal functioning. Deterioration is outside the actor's control in the short run, who can do no more than periodically make good whatever deficit has occurred.

- As regards class 4, at issue are examples where the actor becomes aware that insufficient, too much contradictory, unexpected, incongruent information engages their cognitive skills until they resolve matters.

- As regards class 5, the actor believes that actual or imagined sensory pleasure is available, making them feel deficient until they engage with the experience. 


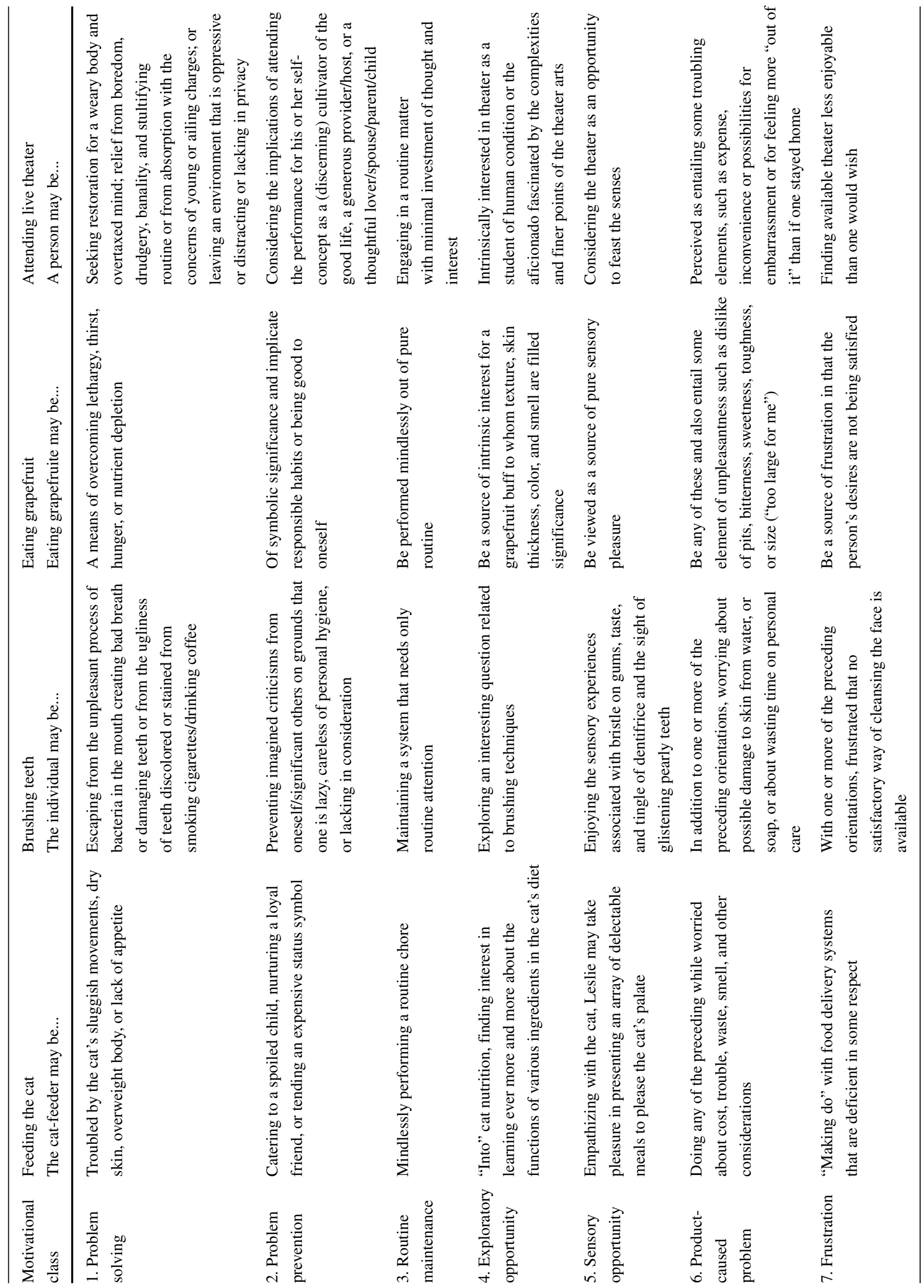


- As regards classes 6 and 7, the individual is already motivated and realizes that taking the indicated action will be unduly costly in any of a variety of ways, e.g., time, effort, physical, or psychological side effects, money (class 6), or futile in that the available actions will not be adequate to the present condition (class 7).

\subsection{Measuring the Presence of Motivating Wants}

Measuring the presence of an individual's concerns and interests that describe their current state is different from measuring the importance of the imagined state associated with owning and using attributes that are available in goods and services. Many product attributes are defining, in the sense that all versions of a product must possess some level of the attribute. For example, all apartments have floor space, all computers have CPUs, and all credit cards have interest rates. In contrast, not all apartments have balconies, so a balcony is not a defining attribute. It is not possible to measure the importance of a defining attribute, only the importance of changing the level of an attribute. As a result, measuring the importance of product features employs an interval scale because the presence of defining attributes rules out the presence of a natural "zero" point.

In contrast, we view motivating conditions as being either present or not present. An individual may not be motivated by any particular want and can certainly have multiple sources of motivation. For example, an individual brushing their teeth can simultaneously be concerned about cavities, bad breath, and social impact. Therefore, a natural zero exists when studying motivating conditions, and there does not exist the concept of a defining attribute. When measuring a motivating condition, the researcher must allow for its possible absence.

The objects of analysis when studying motivating wants are conditions that people experience in the context of an activity. Writing the questionnaire and toothbrushing occasions are described in terms of the concerns and interests present, and the similarity of the description to the respondent's own toothbrushing concerns and interests is used as a basis for inferring importances. In contrast, the objects of analysis in a traditional conjoint study are attributes of product offerings, and the importance of attributes and their levels is derived using preference data.

We use a conjoint-like technique for measuring motivating conditions. Hypothetical toothbrushing occasions are described by the concerns and interests present, and the dependent variable is the similarity of the description to the respondent's own concerns and interests as reported. Respondents are instructed to reflect on a specific occasion of an activity (e.g., the last time you brushed your teeth) and indicate the perceived similarity of the descriptions to their own motivations. Since the concerns and interests that lead individuals to their actions are ratio-scaled, it is important to include a "null" description in which none of a set of motivating conditions is present. Figure 2 provides an example set of stimuli for toothbrushing.

Other aspects of the design of the stimuli and analysis of the responses are identical to traditional conjoint analysis [18]. The stimuli can be constructed using methods of experimental design, including the use of fractional factorial designs $[4,22]$. The dependent variable can be choices, ranks or ratings, and likelihood specified as a linear or latent linear model (see [24]). Moreover, respondent heterogeneity can be incorporated into the analysis using continuous [5], finite mixture densities [21], and continuous mixture models with covariates $[10,27]$.

\section{Method}

We investigate differences between motivating and instrumental wants by comparing the concerns and interests that lead individuals to brush their teeth with the importance of toothpaste attributes and benefits. Concerns and interests for toothbrushing were obtained from qualitative studies that included focus groups among prospects (see [28]) in which the moderator used the motivation classes to guide discussion. Table 2 displays the 31 candidate concerns and interests used in our analysis.

The attributes and benefits $(\mathrm{a} / \mathrm{b})$ of toothpaste are displayed in Table 3. These items are matched to correspond to the concerns and interest (c/i) items in Table 2. For example, the toothpaste benefit "helps remove stains" corresponds to concern "my teeth stain easily"; "helps take away morning breath" corresponds to the concern "I wake up with a bad taste/feeling in my mouth."

Table 4 lists the toothbrushing c/i items in Table 2 next to the corresponding toothpaste $\mathrm{a} / \mathrm{b}$ items in Table 3 . The match between the $\mathrm{c} / \mathrm{i}$ and $\mathrm{a} / \mathrm{b}$ items is intended to be close, with the difference only reflecting the change in the wording needed to move from the c/i object (i.e., motivating conditions that hypothetical people experience) to the $\mathrm{a} / \mathrm{b}$ object (i.e., attributes of hypothetical product offerings) of analysis. By an oversight, we did not write an a/b corresponding to the c/i "toothpastes claim more than they can deliver." Overall, 30 out of the $31 \mathrm{c} / \mathrm{i}$ items were matched to $\mathrm{a} / \mathrm{b}$ items.

The presence and importance of the $\mathrm{c} / \mathrm{i}$ and $\mathrm{a} / \mathrm{b}$ items was measured using a conjoint model based on rank data. For the c/i items, ten sets of stimuli (see Table 2) were provided to respondents with each set comprising four triplets. Ranks were obtained for each of the four toothbrushing occasions described. Each triplet comprises three $\mathrm{c} / \mathrm{i}$ items, and respondents indicated the agreement between these statements and their own c/i's during the last time 
Fig. 2 Example stimuli for measuring the importance of motivating conditions
QUESTION 1

\begin{tabular}{|c|}
\hline Person BJ \\
\hline $\begin{array}{c}\text { Stains, bad } \\
\text { taste/feeling in my } \\
\text { mouth and gums aren't } \\
\text { a problem for me }\end{array}$ \\
\hline $\begin{array}{c}\text { Sensitive teeth, tartar, } \\
\text { plaque and bad breath } \\
\text { aren't a problem for } \\
\text { me. }\end{array}$ \\
\hline $\begin{array}{c}\text { Regularly brushing my } \\
\text { teeth doesn't figure in } \\
\text { my self image, or the } \\
\text { impression I want to } \\
\text { create. }\end{array}$ \\
\hline
\end{tabular}

\begin{tabular}{|c|}
\hline Person AW \\
\hline My teeth stain easily. \\
\hline $\begin{array}{c}\text { I am predisposed to } \\
\text { having sensitive teeth. }\end{array}$ \\
\hline $\begin{array}{c}\text { I would feel I'm } \\
\text { letting myself down if } \\
\text { I didn't brush } \\
\text { regularly. }\end{array}$ \\
\hline
\end{tabular}

\begin{tabular}{|c|}
\hline Person JD \\
\hline $\begin{array}{c}\text { I am concerned about } \\
\text { the condition of my } \\
\text { gums. }\end{array}$ \\
\hline $\begin{array}{c}\text { I am concerned about } \\
\text { bad breath. }\end{array}$ \\
\hline $\begin{array}{c}\text { I believe that people } \\
\text { expect me to brush } \\
\text { regularly. }\end{array}$ \\
\hline
\end{tabular}

they brushed their teeth. We varied the c/i items comprising the toothbrushing occasions across the ten sets of stimuli, and dummy variable coding was used to parameterize the hypothetical occasions. The rank data were modeled using
Table 2 Concerns and interests for toothbrushing
Problem solving:

A1: My teeth stain easily.

A2: I wake up with a bad taste/feeling in my mouth.

A3: I am concerned about the condition of my gums

A4: I am predisposed to having sensitive teeth.

A5: I am concerned about tartar and plaque build-up on my teeth.

A6: I am concerned about bad breath.

A7: My teeth are dull/not white enough.

A8: I am predisposed to having cavities.

A9: I have trouble getting my kids to brush.

A10: I am concerned there are cavity prone places on my teeth.

A11: I am concerned about germs and mouth infections.

A12: I am concerned about not getting to hard to reach places.

Problem prevention

B1: I would feel I'm letting myself down if I didn't brush regularly

B2: I believe that people expect me to brush regularly.

Routine maintenance:

C1: I don't have problems, worries or interests regarding my teeth. I just brush my teeth regularly.

$\mathrm{C} 2$ : For me, brushing my teeth is just something I do with little thought or interest.
Exploratory opportunity:

D1: I like to try different oral brushing techniques/routines just for a change of pace.

D2: I' $m$ interested in knowing about the science of oral hygiene-including different kinds of brushes and toothpastes.

Sensory opportunity:

E1: I like the tingle I feel in my mouth after I brush.

E2: I enjoy the fresh taste I get from brushing.

E3: I love to see my teeth gleam like pearls.

E4: Bubbling action adds to the sensory pleasure of brushing.

Product-caused problems:

F1: Toothpastes are too strong tasting.

F2: Toothpastes scratch the enamel on my teeth.

F3: Toothpastes irritate my mouth.

F3: Toothpastes irritate my mouth.

F4: Toothpastes cost too much.

F5: Toothpastes contain artificial ingredients.

F6: Toothpaste packaging can be harmful to the environment.

Frustration:

G1: Toothpastes aren't strong enough to prevent cavities.

G2: Toothpaste breath-freshening doesn't last long enough.

G3: Toothpastes claim more than they can deliver. 
Table 3 Attributes and benefits of toothpaste

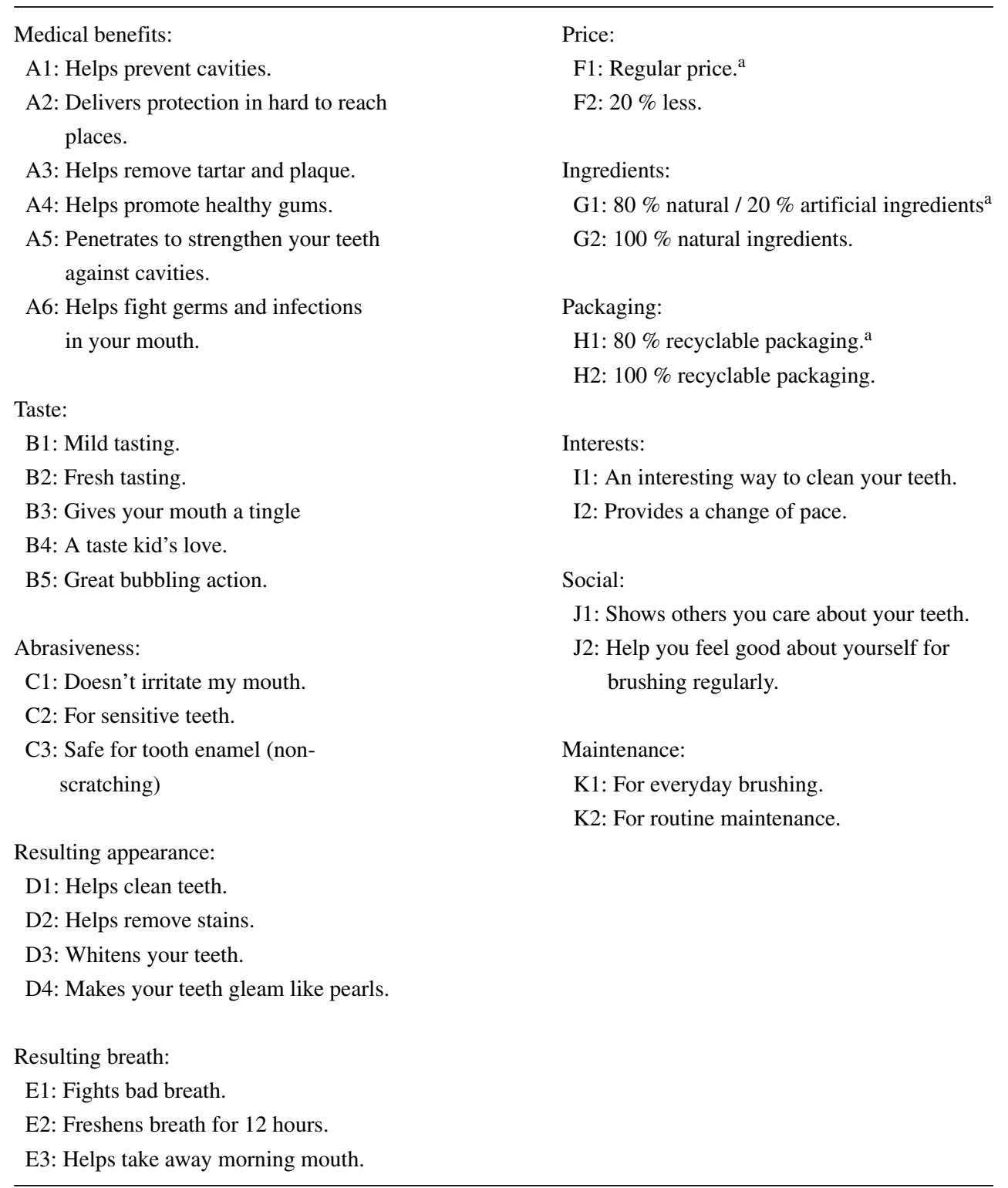

${ }^{\mathrm{a}}$ Null conditions

a logit model, in which the probability of observing a particular rank ordering for the four triplets presented together is equal to:

$$
\operatorname{Pr}\left(U_{1 j}>U_{2 j}>U_{3 j}>U_{4 j}\right)_{h}=\prod_{i=1}^{3} \frac{\exp \left(z_{i j}{ }^{\prime} \gamma_{h}\right)}{\sum_{k=i}^{4} \exp \left(z_{k j}{ }^{\prime} \gamma_{h}\right)}
$$

where $U_{1 j}$ is assumed to be the triplet with highest rank in the $j$ th stimulus set, $U_{2 j}$ has the second highest rank, etc., $z_{i j}$ is the dummy variable coding of the c/i's for the $i$ th-ranked triplet in the $j$ th set, and $\gamma_{h}$ is the vector of $\mathrm{c} / \mathrm{i}$ importance weights for the respondent $(h)$.
One triplet of c/i items in each set of four comprises items describing the absence of the motivating conditions present in the other three triplets (see Fig. 2, left column). As noted earlier, the c/i items can each either be present or absent on an occasion for the focal activity, and it is necessary to measure the absence of a motivating condition as well as its presence. We represent the hypothetical "null" condition by a vector $z$ with elements all equal to zero. This coding scheme leads to estimates of the elements of $\gamma$ which, if positive, indicate the presence of the corresponding motivating condition, and, if negative, correspond to the absence of the condition. The magnitude of the coefficient indicates 
Table 4 Concerns/interests and matched attributes/benefits
Concerns and interests Attributes and benefits

A1: My teeth stain easily.

A2: I wake up with a bad taste/feeling in my mouth.

A3: I am concerned about the condition of my gums

A4: I am predisposed to having sensitive teeth.

A5: I am concerned about tartar and plaque buildup on my teeth.

A6: I am concerned about bad breath.

A7: My teeth are dull/not white enough.

A8: I am predisposed to having cavities.

A9: I have trouble getting my kids to brush.

A10: I am concerned there are cavity prone places on my teeth.

A11: I am concerned about germs and mouth infections.

A12: I am concerned about not getting to hard to reach places.

B1: I would feel I'm letting myself down if I didn't brush regularly.

B2: I believe that people expect me to brush regularly.

C1: I don't have problems, worries or interests regarding my teeth. I just brush my teeth regularly.

$\mathrm{C} 2$ : For me, brushing my teeth is just something I do with little thought or interest.

D1: I like to try different oral brushing techniques/ routines just for a change of pace

D2: I'm interested in knowing about the science of oral hygiene - including different kinds of brushes and toothpastes.

E1: I like the tingle I feel in my mouth after I brush.

E2: I enjoy the fresh taste I get from brushing.

E3: I love to see my teeth gleam like pearls.

E4: Bubbling action adds to the sensory pleasure of brushing.

F1: Toothpastes are too strong tasting.

F2: Toothpastes scratch the enamel on my teeth.

F3: Toothpastes irritate my mouth.

F4: Toothpastes cost too much.

F5: Toothpastes contain artificial ingredients.

F6: Toothpaste packaging can be harmful to the environment.

G1: Toothpastes aren't strong enough to prevent cavities.

G2: Toothpaste breath-freshening doesn't last long enough.

G3: Toothpastes claim more than they can deliver.
D2: Helps remove stains.

E3: Helps take away morning breath.

A4: Helps promote healthy gums.

C2: For sensitive teeth.

A3: Helps remove tartar and plaque.

E1: Fights bad breath.

D3: Whitens your teeth.

A1: Helps prevent cavities.

B4: A taste kid's love.

A5: Penetrates to strengthen your teeth against cavities.

A6: Helps fight germs and infections in your mouth.

A2: Delivers protection in hard to reach places.

J2: Helps you feel good about yourself for brushing regularly.

J1: Shows others you care about your teeth.

K2: For routine maintenance.

K1: For everyday brushing.

I2: Provides a change of pace.

I1: An interesting way to clean teeth.

B3: Gives your mouth a tingle.

B2: Fresh tasting.

D4: Makes your teeth gleam like pearls.

B5: Great bubbling action.

B1: Mild tasting.

C3: Safe for tooth enamel (non-scratching).

C1: Doesn't irritate your mouth.

F2: $20 \%$ less than regular price.

G2: $100 \%$ natural ingredients.

$\mathrm{H} 2: 100 \%$ recyclable packaging.

D1: Help clean teeth.

E2: Freshens breath for 12 hours. 
likelihood of absence $(-)$ or presence $(+)$ of the item to the respondent.

The importance of the $a / b$ items is measured in a similar fashion. Hypothetical product offerings described by the $\mathrm{a} / \mathrm{b}$ items were presented to the respondent, who was asked to provide a rank ordering of the objects in terms of their preference. Ten sets of stimuli were presented, with each comprising four hypothetical product offerings described by three attribute-levels. Respondents were told that the $\mathrm{a} / \mathrm{b}$ items not listed in the description were the same for the offerings. The likelihood of the rank ordering for the four triplets in one of the sets is equal to:

$$
\operatorname{Pr}\left(V_{1 m}>V_{2 m}>V_{3 m}>V_{4 m}\right)_{h}=\prod_{i=1}^{3} \frac{\exp \left(x_{i m}{ }^{\prime} \beta_{h}\right)}{\sum_{j=i}^{4} \exp \left(x_{j m}{ }^{\prime} \beta_{h}\right)}
$$

where $V_{1 m}$ is assumed to be the utility of the hypothetical product offering with the highest rank in the $m$ th set, $x_{i}$ is the dummy variable coding of the a/b's for the $i$ th ranked offering in set $\mathrm{m}$, and $\beta_{h}$ is the vector of $\mathrm{a} / \mathrm{b}$ importance weights (part-worths) for respondent $h$.

In contrast to the coding for the c/i analysis, we do not include a null alternative in each of the four triplet product offering sets. The null attribute-levels for the $a / b$ analysis are indicated by footnote a in Table 3: F1 (regular price); G1 (80\% natural/20\% artificial ingredients); and $\mathrm{H} 1$ (80\% recyclable packaging). We view the attributes of price, ingredients and packaging as defining, and the remaining attributes as optional for toothpaste. For example, toothpastes can exist that do not provide any medical benefit, or have any taste, or any breath-freshening properties. It is possible to describe toothpaste without reference to these attributes.

Despite the lack of a null offering in each of ten triplets, the model for estimating the $a / b$ part-worths from the product rank data is statistically identified. The likelihood for an individual's ranks is defined across all ten triplets:

$$
\begin{aligned}
\ell\left(\gamma_{h} \mid \text { Data }\right) & =\prod_{j=1}^{10} \operatorname{Pr}\left(U_{1 j}>U_{2 j}>U_{3 j}>U_{4 j}\right)_{h} \\
& =\prod_{j=1}^{10} \prod_{i=1}^{3} \frac{\exp \left(z_{i j}{ }^{\prime} \gamma_{h}\right)}{\sum_{k=i}^{4} \exp \left(z_{k j}{ }^{\prime} \gamma_{h}\right)} \\
\ell\left(\beta_{h} \mid \text { Data }\right) & =\prod_{m=1}^{10} \operatorname{Pr}\left(V_{1 m}>V_{2 m}>V_{3 m}>V_{4 m}\right)_{h} \\
& =\prod_{m=1}^{10} \prod_{i=1}^{3} \frac{\exp \left(x_{i m}{ }^{\prime} \beta_{h}\right)}{\sum_{j=i}^{4} \exp \left(x_{j m}^{\prime} \beta_{h}\right)}
\end{aligned}
$$

Therefore, the identifying restrictions for the model extend beyond the specific $a / b$ items present in any one of the triplets. It is not possible to arbitrarily increase the value of any or all of the elements of $\beta_{h}$ without changing the value of the likelihood for the entire set of ranks.

Heterogeneity is incorporated into the model specification by assuming a random-effects distribution for the parameters:

$\theta_{h}=\left(\gamma_{h}{ }^{\prime}, \beta_{h}{ }^{\prime}\right)^{\prime} \sim \operatorname{Normal}(\mu, \Sigma)$

Markov chain Monte Carlo (MCMC) methods are used to estimate the model parameters. The chain was run for a total of 50,000 iterations, with parameter estimates based on the last 10,000 iterations. We investigate multiple start points and found the chain to converge to a common posterior distribution. The estimation algorithm is provided in the Online Appendix.

\section{Data and Parameter Estimates}

Data were obtained from a nationally representative panel in mailed questionnaires administered by a leading marketing research firm. 863 completed surveys were available for analysis. The data in the survey included ten sets of stimuli each comprising four triplets of c/i descriptions of toothbrushing occasions, and ten sets of stimuli each comprising four triplets of $\mathrm{a} / \mathrm{b}$ descriptions of toothpaste. Brand belief ratings for Aquafresh, Colgate, Crest and Mentadent were also obtained by asking respondents to rate each brand on each of the $30 \mathrm{a} / \mathrm{b}$ items using a five-point scale where "5" means "describes completely" and "1" means "does not describe at all." For example, respondents were asked to indicate the degree to which attribute A1: "Helps prevent cavities" describes each brand, and so on. Finally, actual brand use information was obtained by asking respondents to identify whether they usually buy a particular brand of toothpaste, and if so, which brand. Estimates of the mean of the random-effect distribution are reported in Table 5. Estimates of the covariance matrix $\Sigma$ are not reported but are available from the authors upon request. The fit of the model described by Eqs. 3-5 is good, with an average insample hit probability of 0.60 . We find that the responses to the $\mathrm{c} / \mathrm{i}$ and $\mathrm{a} / \mathrm{b}$ items were of equal consistency as measured by in-sample fit.

Estimates of the mean of the random-effects distribution for the $c / i$ items are different than those for the $a / b$ items. The most prevalent c/i item is B1 "I would feel I'm letting myself down if I didn't brush regularly" with an average importance of 3.211 and a posterior standard deviation of 0.132 . The most important $\mathrm{a} / \mathrm{b}$ item is B3 "Gives your mouth a tingle" with an average importance of 1.658 and 


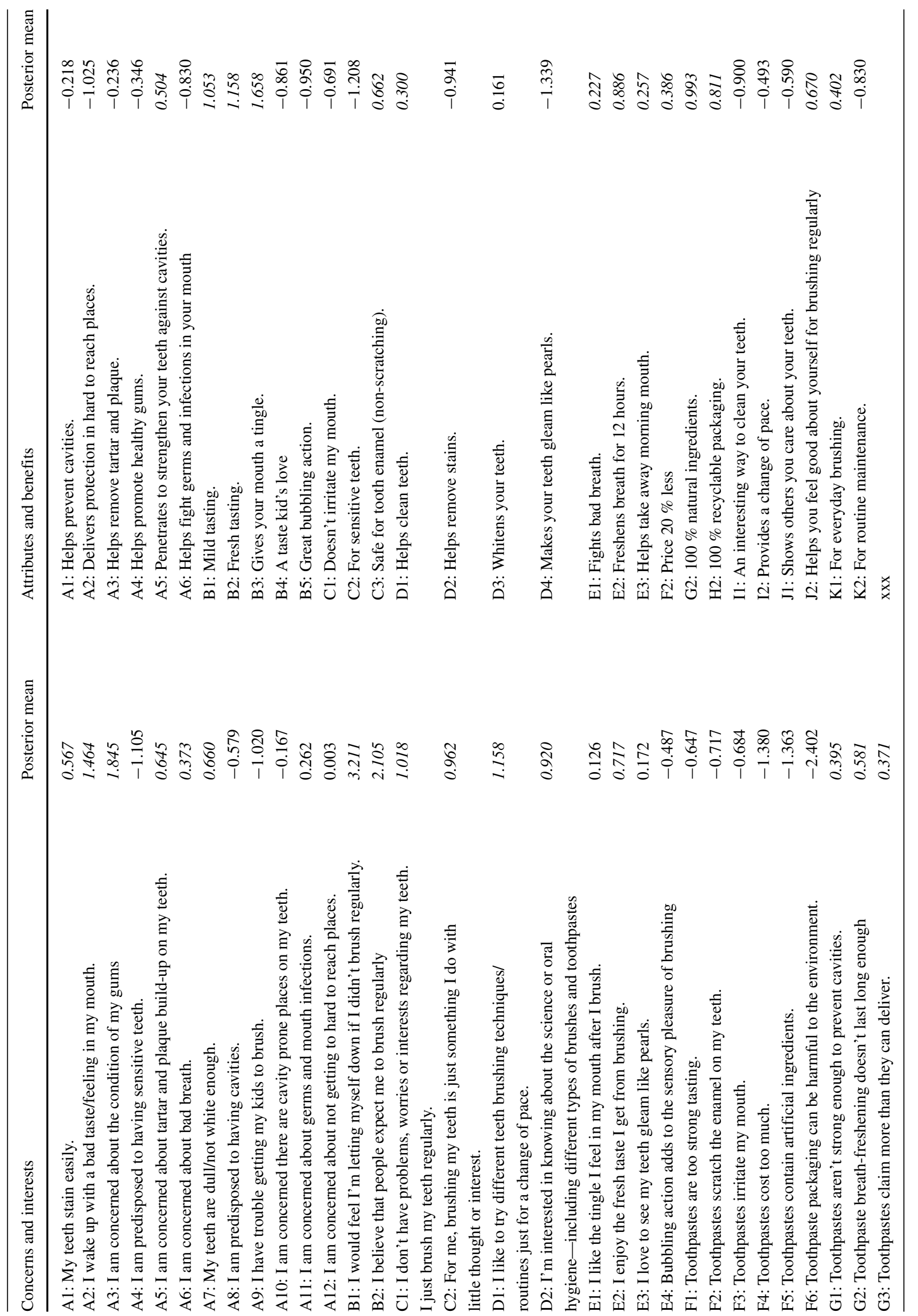

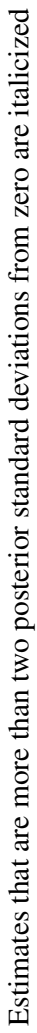


a posterior standard deviation of 0.070 . Thus, a different view of wants emerges from studying c/i's and a/b's respectively. The two most present c/i items are B1 "I would feel I'm letting myself down if I didn't brush regularly" and B2 "I believe that people expect me to brush regularly." The ranks of the corresponding $\mathrm{a} / \mathrm{b}$ items are 7 and 20 . The most important a/b items deal with taste attributes: B3 "Gives your mouth a tingle," B2 "Fresh tasting," and B1 "Mild tasting." The associated c/i ranks are 20, 9, and 24.

In the next section we explore the source of the differences between the $\mathrm{c} / \mathrm{i}$ and $\mathrm{a} / \mathrm{b}$ analyses. Respondents appear to interpret statements such as "I believe that people expect me to brush regularly," very differently from statements such as "Shows others you care about your teeth." The two sets of items are clearly providing different implications for product policy, despite our having closely matched the $\mathrm{a} / \mathrm{b}$ and $\mathrm{c} / \mathrm{i}$ items.

\section{Findings}

In this section we document three limitations of using attribute preferences to measure prospective user wants. First, we find that attribute-level part-worth estimates $(\beta)$ are confounded with the capabilities of current offerings, while the presence of the concerns and interests $(\gamma)$ are unrelated to these capabilities. Attribute preferences therefore do not offer an independent assessment of market demand. Second, we find evidence of a complex relationship between $(\gamma)$ and the attribute-level part-worths $(\beta)$. Hence, knowledge of attribute importance is not sufficient for understanding motivating conditions. Finally, we show that the concerns and interests $(\gamma)$ can be used in conjunction with the attribute-level part-worths $(\beta)$ to improve brand choice predictions. This indicates that the current array of attributes and levels do not completely respond to the existing motivating wants of individuals, providing indication of unmet demand in the marketplace. The analysis reported below employs the parameter estimates reported above, in conjunction with the analysis of data on brand belief ratings and brand use that were collected during the survey.

\subsection{The Confounding Influence of Current Capabilities}

Figure 3 provides a plot of the average importance of the c/i items versus the average brand belief ratings for Aquafresh, Colgate, Crest and Mentadent on each of the $a / b$ items. The importance of the c/i items is measured in terms of the mean of the random-effects distribution of $\gamma$ reported on the left side of Table 6 . For each of the $30 \mathrm{c} / \mathrm{i}$ items that have a matched attribute and benefit (see Table 5), brand belief ratings, measured on the five-point "describes completely"/"not at all" scale, were averaged over the four brands. This procedure results in the respondents' average brand belief ratings of leading brands in the product category on items corresponding to the $\mathrm{c} / \mathrm{i}$ items. Data labels (e.g., H2) refer to toothpaste attributes and benefits listed in Table 2.

Figure 3 contains three outliers defined as observations that are away from the bulk of the data. The three outliers correspond to extreme levels of the attributes: uses $100 \%$ recyclable packaging and $100 \%$ natural ingredients and freshens breath for $12 \mathrm{~h}$. For the remaining c/i items, the correlation between the average importance and the average brand rating is near zero $(r=0.02, p=0.91)$.

Figure 4 provides a corresponding plot for the $\mathrm{a} / \mathrm{b}$ items. The three outliers are more pronounced in this figure, clearly separated from the rest of the data. Respondents place a high value on the attribute-levels of the outliers, but feel that the leading brands are not well described by the extreme levels of these attributes. The remaining points in the plot exhibit a fairly strong association $(r=0.52$, $p=0.01$ ) between the average brand belief rating and the $a / b$ coefficients, suggesting that there may be a confounding influence between the importance of an attribute-level and the ability of the currently available brands to offer corresponding value. Data labels (e.g., H2) refer to toothpaste attributes and benefits listed in Table 3 .

\subsection{Motivational Ambiguity}

The presence of a confounding influence of the current brands is just one reason that analysis based on c/i items would differ from analysis based on $a / b$ items. Another reason is the presence of motivational ambiguity, where consumers may construe a particular attribute or benefit to be responsive to their $\mathrm{c} / \mathrm{i}$, which is unobserved to the researcher. We argue that the relationship between the $\mathrm{a} / \mathrm{b}$ and c/i items is not as simple as the paired relationship displayed in Table 4 due to cross-sectional heterogeneity. If the relationship were in fact paired uniformly among respondents, then the correlation structure of the $\beta$ and $\gamma$ items would be similar, with any associations among the $\beta$ items also present among the $\gamma$ items.

Our estimate of the covariance matrix (reported in the online appendix) has 380 of the 930 covariances between the $\gamma$ and $\beta$ elements with posterior mass away from zero, indicating the likely presence of cross-sectional ambiguity where different respondents see different $\mathrm{a} / \mathrm{b}$ items as a response to a particular $\mathrm{c} / \mathrm{i}$. We find, for example, that the cross-sectional association among the $\mathrm{c} / \mathrm{i}$ items $(\mathrm{B} 1, \mathrm{~B} 2)$ and (E1, E2, E3) is uniformly positive, while the corresponding associations in terms of the $\mathrm{a} / \mathrm{b}$ items $(\mathrm{J} 1, \mathrm{~J} 2)$ and $(\mathrm{B} 1, \mathrm{~B} 2$, B3) are both positive and negative. Despite the close match between them as shown in Table 4, the presence of both 
Fig. 3 Presence of C/I vs. average brand ratings

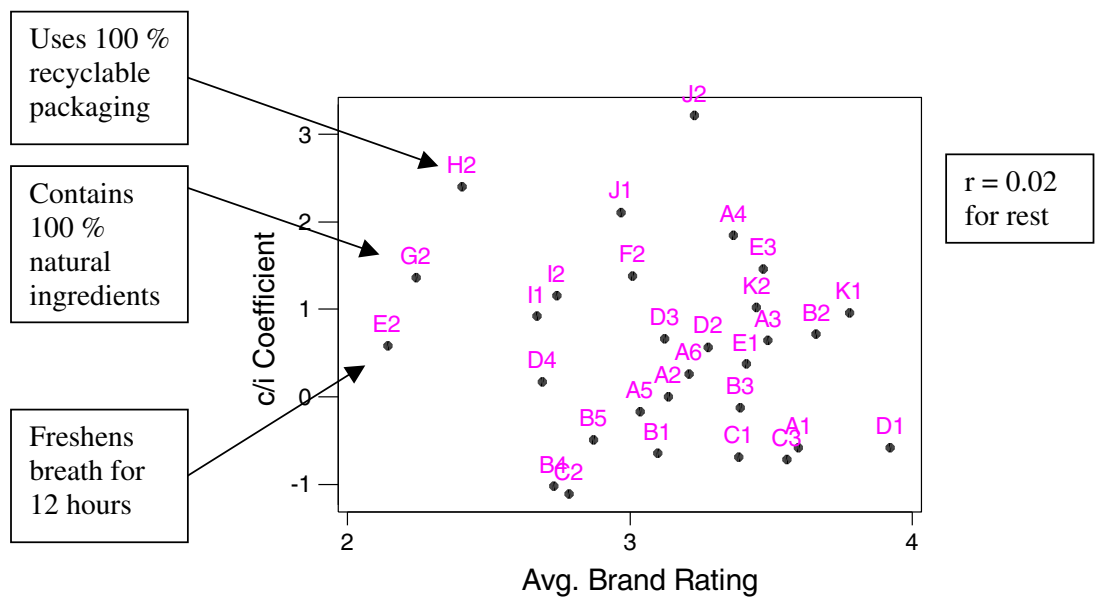

positive and negative covariations among c/i and $\mathrm{a} / \mathrm{b}$ items indicates that prospects may mistakenly read into claimed attributes of offerings $(\mathrm{a} / \mathrm{b})$ as a response to the conditions they experience (c/i). Individuals who are concerned that "I would feel I'm letting myself down if I didn't brush regularly" prefer the a/b "Gives your mouth a tingle" and may construe a tingling sensation as being responsive to this social concern [15].

\subsection{Predictive Performance}

The degree to which an analysis of attributes and benefits fully reflects the range of motivating wants, or is located in an optimal region of demand, can be partially assessed by its predictive relationship to actual brand use. We caution, however, in using brand predictions as the only standard for assessing the information content of attributes and benefits. As illustrated in Fig. 1, the movement from attribute preferences to actual brand purchase involves a number of constructs that are not studied in our analysis, including consideration sets and shelf prices. While we view the prediction of brand use as informative about the information contained in $\mathrm{a} / \mathrm{b}$ and $\mathrm{c} / \mathrm{i}$ items, we note that our analysis is limited to a subset of important variables.

We assess the predictive performance of the $\mathrm{c} / \mathrm{i}$ and $\mathrm{a} / \mathrm{b}$ items by using them to weigh the brand belief ratings data collected for the Aquafresh, Colgate, Crest, and Mentadent brands to arrive at an overall score for each brand. The brand with the highest score is predicted to be the brand that the respondent will use, and this prediction is compared to the actual brand used by the respondent as reported in the questionnaire.

We employ a Bayesian approach to measuring predictive performance using likelihood ratios. The predicted (P) and true (T) choices for each brand are related using Bayes' theorem:

$$
\frac{\operatorname{Pr}(\mathrm{T}=+\mid \mathrm{P}=+)}{\operatorname{Pr}(\mathrm{T}=-\mid \mathrm{P}=+)}=\frac{\operatorname{Pr}(\mathrm{T}=+)}{\operatorname{Pr}(\mathrm{T}=-)} \times \frac{\operatorname{Pr}(\mathrm{P}=+\mid \mathrm{T}=+)}{\operatorname{Pr}(\mathrm{P}=+\mid \mathrm{T}=-)}
$$

or

Posterior Odds $=$ Prior Odds $\times$ Likelihood Ratio

where "+" indicates that the brand is actually chosen or predicted to be chosen and "-_" otherwise.

The "Prior Odds" is equal to the odds of brand preference without knowledge of the $\mathrm{c} / \mathrm{i}$ or $\mathrm{a} / \mathrm{b}$ information. The posterior odds is the prediction of brand preference given information from the $\mathrm{c} / \mathrm{i}$ or $\mathrm{a} / \mathrm{b}$ (or both), plus information about the prior odds. The likelihood ratio summarizes the predictive information from the $\mathrm{c} / \mathrm{i}$ and $\mathrm{a} / \mathrm{b}$ about the true preferences. When the likelihood ratio is greater than 1 , the posterior odds are greater than the prior odds, and when the ratio is less than 1 , the posterior odds are less than the prior odds. We would expect a $L R>1$ when the prediction is + and a $L R<1$ when the prediction is - . The likelihood ratios were computed for 578 of the 863 respondents. The 285 respondents not included in the predictive analysis either did not provide brand ratings information or used a brand that was different from the four brands in our analysis.

Table 7 displays the likelihood ratios for each brand, using the $\mathrm{a} / \mathrm{b}$ and $\mathrm{c} / \mathrm{i}$ importances to weigh the brand ratings to obtain an overall measure of brand value. As expected, the likelihood ratios are greater than 1 when the brand is predicted to be the favorite brand and less than 1 when the brand is predicted to not be the favorite brand. This indicates that the $a / b$ and $c / i$ importance measures have predictive validity. In addition, we find that the c/i's lead to likelihood ratios that are more predictively accurate than the a/b's, with 


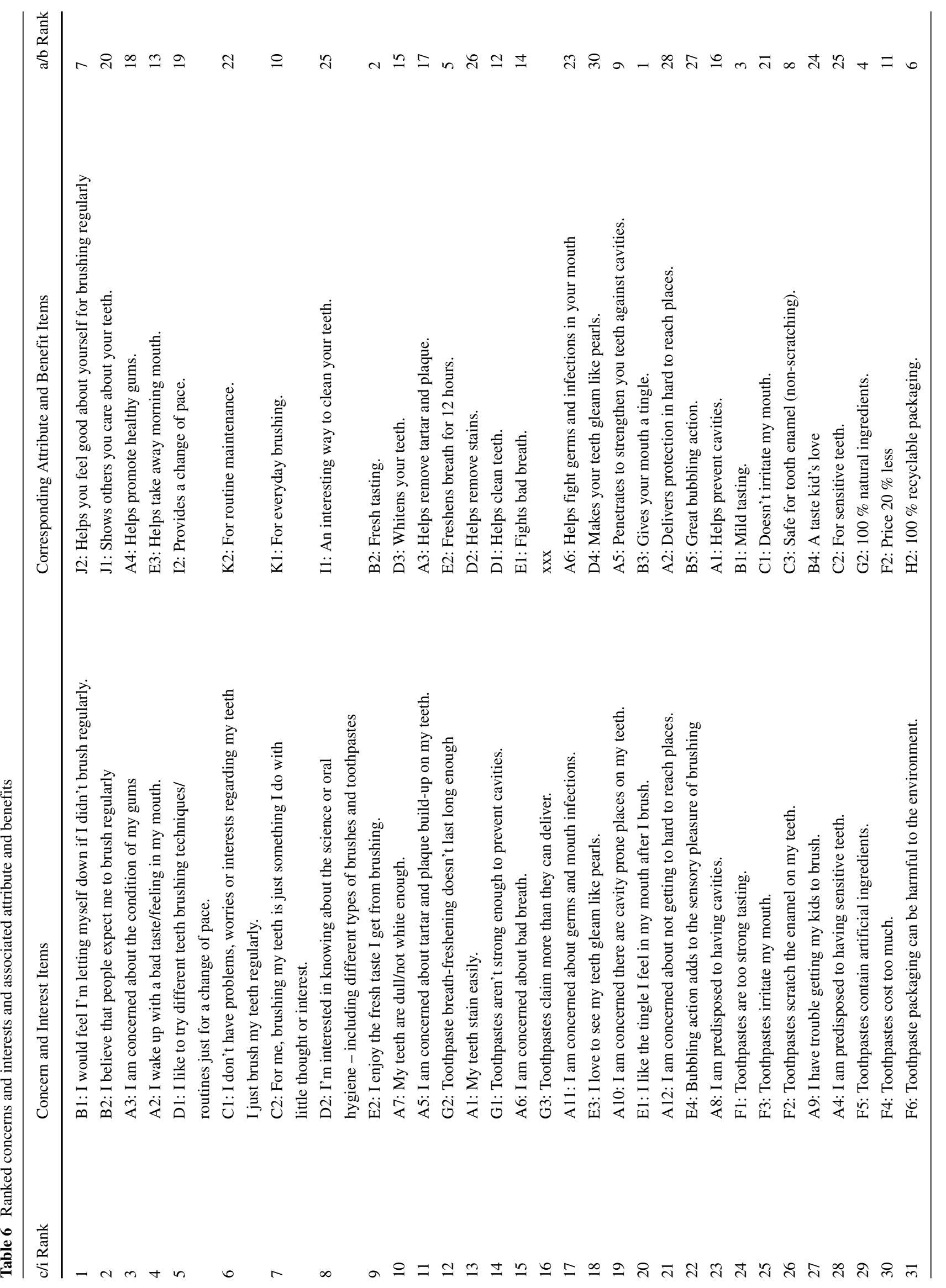


Fig. 4 Importance of a/b vs. average brand ratings

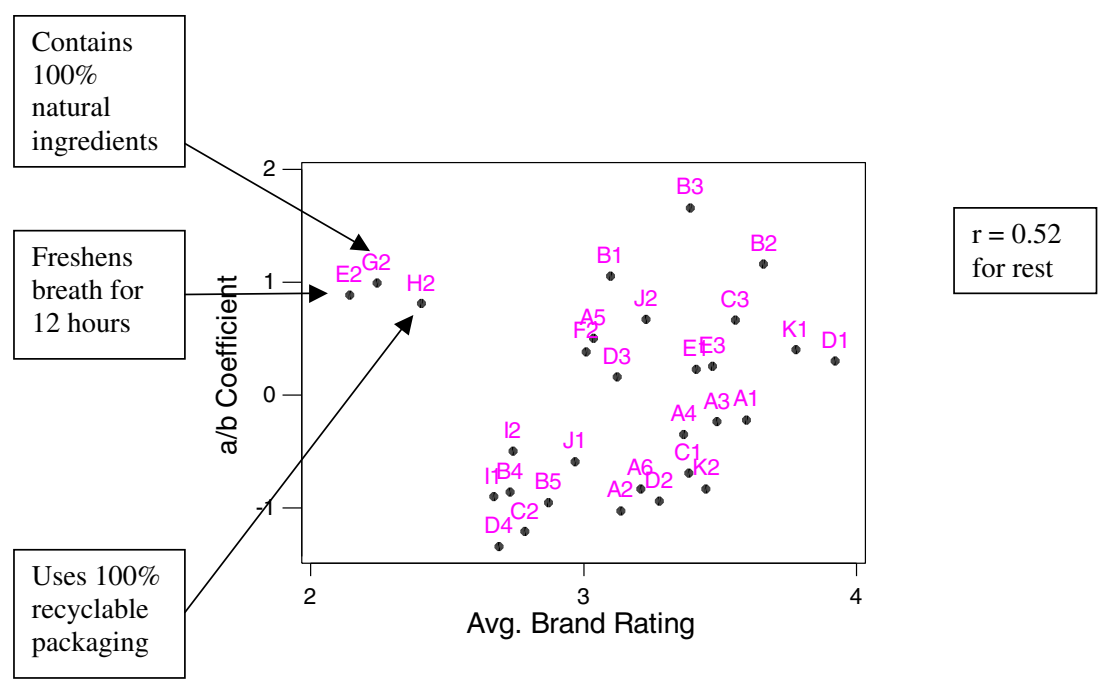

larger ratios when the prediction is positive and smaller ratios (closer to zero) when the prediction is negative.

The bottom portion of Table 7 reports likelihood ratios based on both the c/i's and the a/b's. When the weighted ratings are positive for both the $\mathrm{c} / \mathrm{i}$ 's and $\mathrm{a} / \mathrm{b}$ 's, the likelihood ratios are approximately equal to four, indicating that the prior odds are increased by a factor of 4 to yield posterior odds that a brand is preferred by a respondent. The fact that the combined likelihood ratios are greater than either of the individual likelihood ratios indicates that the c/i's and a/b's reflect different aspects of demand, with the c/i's capturing motivating conditions that are upstream and independent of current offerings.

Table 7 Likelihood ratios

\begin{tabular}{llll}
\hline Attribute/benefit & Positive (+) & Negative (-) & \\
Aquafresh & 1.86 & 0.74 & \\
Colgate & 1.75 & 0.79 & \\
Crest & 2.04 & 0.78 \\
Mentadent & 2.46 & 0.65 & \\
& & & \\
Concerns/interests & Positive (+) & Negative (-) & \\
Aquafresh & 2.25 & 0.69 & \\
Colgate & 2.53 & 0.70 & \\
Crest & 3.00 & 0.69 & \\
Mentadent & 2.17 & 0.62 & Both negative \\
& & & $(-,-)$ \\
& Both positive & One positive & \\
Both & $(+,+)$ & $(+,-$ or,-+$)$ & 0.58 \\
Aquafresh & 3.87 & 1.29 & 0.59 \\
Colgate & 3.73 & 1.48 & 0.58 \\
Crest & 7.82 & 1.55 & 0.40 \\
Mentadent & 4.21 & 1.58 & \\
\hline
\end{tabular}

\section{Discussion}

Wants originate upstream from the marketplace, in the context of everyday life. Individuals find value in marketplace offerings that are responsive to the concerns and interests that lead them to engage in the activities of their lives. Preferences for product attributes therefore result from people searching for correspondence between upstream conditions that lead them to action and the capability of marketplace offerings to deliver utility within the activity. In this paper, we introduce a method of augmenting the standard analysis based on reactions to marketplace offerings by identifying the concerns and interests that specify valued attributes.

Research on wants in marketing has focused on the imagined state of an individual, either in terms of the end state itself (e.g., goals, benefits) or instruments helpful in getting there (e.g., the part-worths of product attribute-levels). In this paper, we report on the research that includes measures both of the present and the desired state. The present state is described in terms of concrete concerns and interests relevant for brand purchase; the desired state is described in terms of the usual product benefits/attributes. The additional measure differs from product benefits/attributes in a number of respects:

1. It measures motivating features of the context in which prospects engage in the activity for which the product benefits/attributes should be relevant. In other words, it describes the conditions to which product attributes/benefits should be responsive, if prospects are to value them.

2. In place of the purely empirical approach to generating product attributes and benefits associated with the imagined state, our measure is derived from a set of seven qualitatively distinct classes of motivating conditions. These classes cover a range of qualitatively 
diverse condition, whereas no such platform has been available from which to judge the comprehensiveness or possible redundancy of product attributes and benefits.

3. A generally accepted motivational formulation speaks of motivation as arising when, comparing a current state with an imagined/desired state, an individual allocates resources to trying to bring about the desired state. In light of such a formulation, wants up to now have been studied in ways that are relevant to the second of these two states, i.e., the imagined/desired state. Conceptually, our new measure operationalizes the motivating features of the current state, i.e., present features whose absence, or absent features whose presence, defines the desired state.

The concerns and interests that lead individuals to the pursuits in their lives exist whether or not managements respond with appropriate goods and services. Concern about bad breath or dull teeth may not be satisfied within the current array of toothpaste offerings, leaving the individual wanting or deprived. The presence of a motivating want without a corresponding marketplace offering (e.g., social expectations about toothbrushing and the absence of a toothpaste that shows others you care about your teeth) can be regarded as unmet demand. A limitation of using marketplace preferences as a guide to prospect wants is that there is no guarantee that the analysis fully reflects the range of motivating wants among potential users.

If there is no guarantee that an analysis of marketplace preference fully reflects the range of motivating conditions, then the analysis of marketplace offerings must consider its location in the demand space. However, the offerings used in the analysis of preferences often arise from the array of currently available goods and services, whose existence is nonsystematic. In a conjoint study, for example, hypothetical offerings are constructed with feature combinations that are typically within, or close to, the convex hull of existing offerings. The evolution of actual offerings builds incrementally on past actions and is dependent on current and feasible technologies. Analysis based on product offerings may therefore be located in a portion of the demand space that is suboptimal for marketing's role in guiding product policy.

The analysis of preference also leads to unclear direction for product policy because of motivational ambiguity [12]. Consider, for example, the reasons that consumers prefer toothpaste that "gives your mouth a tingle." Preference for a sharp taste may be due to sensory enjoyment of the tingle or because consumers construe this attribute as responsive to concerns about letting oneself down, the expectations of others, or the possibility of tartar and plaque buildup. Simply knowing which features are preferred does not provide access to the nature of conditions that lead people to act and find value in the offering. Such information is often critical so that management can optimally generate and choose among options for brand formulation and communication strategy (see [3]).

Such limitations of using preferences to guide product policy are present because wants are conceptualized and measured in terms of an array of real or hypothetical offerings. We offer a conceptualization of wants in terms of motivating conditions that are independent of marketplace offerings and develop a conjoint-based approach to measuring their importance. These motivating wants are the source of brand preference and can provide substantive guidance for product formulation and communication efforts. Our analysis illustrates that attribute-level part-worths can be correlated with brand belief ratings (Fig. 4), that there exists motivational ambiguity in terms of the complex mapping among $\mathrm{c} / \mathrm{i}$ and $\mathrm{a} / \mathrm{b}$ items, and that the $\mathrm{c} / \mathrm{i}$ items can be used to improve brand preference.

Both within marketing and economics, authors have sought improved methods of understanding the consumer and, specifically, of investigating what users want from goods and services. Research and analysis, however, is mainly focused on instrumental wants and marketplace offerings. While recent work on extending the scope of these models has included a range of psychological variables (e.g., [9]), it has not offered an explicit operationalization of motivation. In this paper, an explicit operationalization of motivation is offered, and its systematic role in a model of action and brand use is demonstrated. Accordingly, in addition to the economist's ex post view of demand (e.g., instrumental wants expressed as reactions to good/services), marketers can use our approach to study an ex ante view of demand in which motivating wants are expressed as concerns and interests in the context for the everyday activities, for which goods/services are offered and used.

Acknowledgments The authors thank Derek Rucker for the helpful feedback on the paper.

\section{References}

1. Ajzen I (1991) The theory of planned behavior. Organ Behav Hum Decis Process 50(2):179-211

2. Ajzen I, Sheikh S (2013) Action versus inaction: anticipated affect in the theory of planned behavior. J Appl Soc Psychol 43(1):155162

3. Allenby G, Fennell G, Bemmaor A, Bhargava V, Christen F, Dawley J, Dickson P, Edwards Y, Garratt M, Ginter J et al (2002) Market segmentation research: beyond within and across group differences. Mark Lett 13(3):233-243

4. Allenby GM, Ginter JL (1995) Using extremes to design products and segment markets. J Mark Res 32:392-403 
5. Allenby GM, Rossi PE (1998) Marketing models of consumer heterogeneity. J Econ 89(1):57-78

6. Arndt J (1976) Reflections on research in consumer behavior. Adv Consum Res 3:213-221

7. Bagozzi RP, Dholakia U (1999) Goal setting and goal striving in consumer behavior. J Mark 63:19-32

8. Belk RW (1974) An exploratory assessment of situational effects in buyer behavior. J Mark Res 11:156-163

9. Ben-Akiva M, McFadden D, Train K, Walker J, Bhat C, Bierlaire M, Bolduc D, Boersch-Supan A, Brownstone D, Bunch DS et al (2002) Hybrid choice models: progress and challenges. Mark Lett 13(3): $163-175$

10. Chandukala SR, Edwards YD, Allenby GM (2011) Identifying unmet demand. Mark Sci 30(1):61-73

11. Dickson PR (1982) Person-situation: segmentation's missing link. J Mark 46:56-64

12. Fennell G (1978) Consumers' perceptions of the product use situation. J Mark 42:38-47

13. Fennell G (1987) A radical agenda for marketing science: represent the marketing concept. In: Dholakia N, Furat F, Baggozzi $\mathrm{R}$ (eds) Philosophical and radical thought in marketing. D.C. Health, Lexington, pp 289-306

14. Fennell G (1997) Value and values: relevance to advertising. Values, lifestyles, and psychographics. Earlbaum, Hillsdale, pp 83110

15. Fennell G (2012) Marketing insights from a model of action and empirical findings. In: Posavac S (ed) Cracking the code: leveraging consumer psychology to drive profits. M.E. Sharpe, Armonk

16. Fishbach A, Ferguson MJ (2007) The goal construct in social psychology. Soc Psychol Handb Basic Princ 2:490-515

17. Fishbach A, Henderson MD, Koo M (2011) Pursuing goals with others: group identification and motivation resulting from things done versus things left undone. J Exp Psychol Gen 140(3):520
18. Green PE, Srinivasan V (1990) Conjoint analysis in marketing: new developments with implications for research and practice. $\mathrm{J}$ Mark 54(4):3-19

19. Haley RI (1968) Benefit segmentation: a decision-oriented research tool. J Mark 32:30-35

20. Huffman C, Ratneshwar S, Mick DG (2000) Consumer goal structures and goal-determination processes: an integrative framework. In: The why of consumption: contemporary perspectives on consumer motives, goals and desires. Routledge

21. Kamakura W, Russell G (1989) A probabilistic choice model for marketing segmentation and elasticity structure. J Mark Res 23:89-100

22. Lenk P, DeSarbo W, Green PE, Young M (1996) Hierarchical Bayes conjoint analysis: recovery of part-worth heterogeneity from reduced experimental designs. Mark Sci 15:173-191

23. Lewin K (1936) Principles of topological psychology. McGrawHill, New York

24. Marshall P, Bradlow ET (2002) A unified approach to conjoint analysis models. J Am Stat Assoc 97(459):674-682

25. McClelland DC, Atkinson JW, Clark RA, Lowell EL (1976) The achievement motive. Irvington

26. Reynolds TJ, Gutman J (1988) Laddering theory, method, analysis, and interpretation. J Advert Res 28:11-31

27. Rossi PE, Allenby GM, McCulloch R (2005) Bayesian statistics and marketing. Wiley, New York

28. Saegert J, Hoover RJ, Landeck M (1993) Using focus groups to explore domains of action. In: Proceedings of the society for consumer psychology. American Psychological Association, Washington, pp 36-42

29. Wells WD (1993) Discovery-oriented consumer research. J Consum Res 19:489-504

30. Yang S, Allenby GM, Fennell G (2002) Modeling variation in brand preference: the roles of objective environment and motivating conditions. Mark Sci 21(1):14-31 